\title{
Environmental awareness of generation " $Z$ " as a trend in the development of modern hotel business enterprises
}

\author{
Galina Vorontsova ${ }^{1,{ }^{*}, \text { Anna } \text { Vorontsova }^{2} \text {, Victoria Sandrina }}{ }^{1}$, Ekaterina Klein ${ }^{1}$, and Anna \\ Skobeltcyna ${ }^{1}$ \\ ${ }^{1}$ Saint Petersburg State University of Economics, 21 Sadovaya St., 191023 St. Petersburg, Russia \\ ${ }^{2}$ Saint-Petersburg State University of Industrial Technologies and Design, 18 Bolshaya Mosrkaya St., \\ 191186 St. Petersburg, Russia
}

\begin{abstract}
This article covers the analysis of the influence of the pandemic on the development of hospitality facilities in St. Petersburg, determination of their development trends, identification of needs of Generation $\mathrm{Z}$ as a growing segment of hotel services consumers, consideration of the essence of the notion "environmental awareness" in the hospitality industry, mechanisms of its formation in Generation $\mathrm{Z}$ and practical approaches to eco-projects implementation in the industry.
\end{abstract}

\section{Introduction}

The today's persistent and often irrational consumption of resources and services throws the issue of ecological safety into sharp relief. More and more publications devoted to the environmental safety and ecology, harmful consequences for human living and particular fields of the economy have appeared recently, and they are both publicistic and scientific works. People must think over proper consumption, operation, disposal and processing of various products of life and used services. Ethical consumption is not only the issue of buying clothed but also of choosing brands that ensure good labor conditions for their employees, make products of the recycled materials, develop their production facilities with due regard to environmental impact not only of a particular region [1] but the entire global space in general.

The pandemic that had been sweepingly spread demonstrated unsteadiness and vulnerability of the existence of the human community by claiming a great deal of lives and causing considerable economic losses. Tourism and hotel industry has incurred tangible economic losses both in Russia, and in the world. According to experts, the revival of the industry will take several years. One of the key issues of this process will be the use of "green technologies" with possible formation of environmental awareness of hospitality services consumers. Generation $\mathrm{Z}$ will take one of the key positions in this process since this is an ever-growing segment of hotel services consumers, on the one hand, and a new generation of employees of hospitality facilities, on the other hand.

\footnotetext{
*Correspondent author: galina-graf56@mail.ru
} 
According to the generational theory by Neil Howe and William Strauss, Generation Z is generally defined as people born between 1995 and 2010 characterized by certain personal features and behavioural patterns. These often include affection for a lot of digital devices, credibility to opinion leaders, multi-tasking, thoughtfulness and emotional investment in global processes. Sociologists contend that one of the key priorities is safety and wish for public changes. It turns out to be clear why this population has done with a good grace and accepted a trend to rational consumption, careful attitude towards nature and cultures, rallied to the vulnerable population groups' defence and accepted the rules of new ethics. These new social changes reflect both needs of the generation: the world and the society are changing for the better and becoming safer for all people.

That is why it is especially important to send messages of "environmental awareness" to the new generation in order they could do the rethinking and come to conscious consumption of resources and services. Coming to the hotel business, these people as professional employees of the hospitality industry, would have not only to be the protagonists of this idea but to be able to scale it up by offering rational technologies of conscious ecology to the hotel services consumers.

The scientific and practical relevance of our work consists in analysing the influence of the pandemic on the hospitality facilities of St. Petersburg, detailing the term "environmental awareness", mechanisms of its formation in Generation Z, as well as practical development and implementation of eco-projects in the hospitality industry.

\section{Methods of research and task setting}

The influence of the pandemic on the hotel business was analysed by the following parameters:

1) safety measures taken by hotel facilities;

2) operational changes in the organizational structure of hotel facilities and, as a consequence, change of internal standards;

3) digitalization and contactless services with due regard to the use of various digital technologies and forms of guests' services;

4) staff, nature of change in the staff work with due regard to the combination of duties of employees from different departments, transfer of some staff to remote work, staff reduction.

The formed level of environmental awareness in students was assessed by a questionnaire survey including the following issues:

1) knowledge of "green technologies" in tourism and hospitality;

2) participation in ecological projects in tourism and hospitality;

3) understanding the essence and content of the notion "environmental awareness";

4) necessity to study ecological problems in the framework of professional training.

Analysis of the influence of the pandemic on the hotel business in St. Petersburg

The general situation in the hospitality industry shows a considerable reduction in income due to the implementation of Covid measures in St. Petersburg for the hotel business. The system changes in the hotel business are related to increased consumer demand for country hotels, apart hotels, local conceptual hotels. The main peculiar feature of this hotel category is the customer's opportunity to isolate in individual housing and services provided. The average occupancy of apart hotels in the conditions of restrictions made $30 \%$ [2]. To compare, according to JLL, the average weighted occupancy of the international branded hotels in St. Petersburg made 5.2\% in Q2 2020 that was by 93\% lower than in 2019 [3]. The main advantage of apart hotels is the availability of kitchen areas that made it possible easily to adapt to the changed target audience and switch over from the short-term living to the long-term living. 
In the framework of the research, the questionnaire survey of hotel facilities, including $705-3 *$ hotels of St. Petersburg with various room inventory and price segment, was performed, and a series of focus groups made up by experts in the hospitality industry has been organized. In addition to the academic teaching staff of the Department of Hotel and Restaurant Business of the Saint Petersburg State University of Economics, the students of the specialty "Hotel Business" participated in the information collection.

Quotation of hotel facilities was determined by the degree of qualitative changes in the internal standards, staff work regulations and processes during the COVID-19 pandemic. The analysis performed during research made it possible to determine the main problem areas of hospitality facilities:

1) safety - recommendations of the Federal Service for the Oversight of Consumer Protection and Welfare and Orders of Governor A.D. Beglov with due regard to the epidemiological situation

2) functions and internal standards of the hotel facilities, i.e. development of cleanliness maintenance protocols Top Clean And Safety and programs CleanStay Room Seal considered to be additional safety measures; amendments to internal standards relating to interior design, booking and accommodation procedure;

3) digitalization and contactless services, i.e. review of various methods of using mobile applications in guests' servicing, 3D navigators, VR- and AR technologies and forms of contactless services;

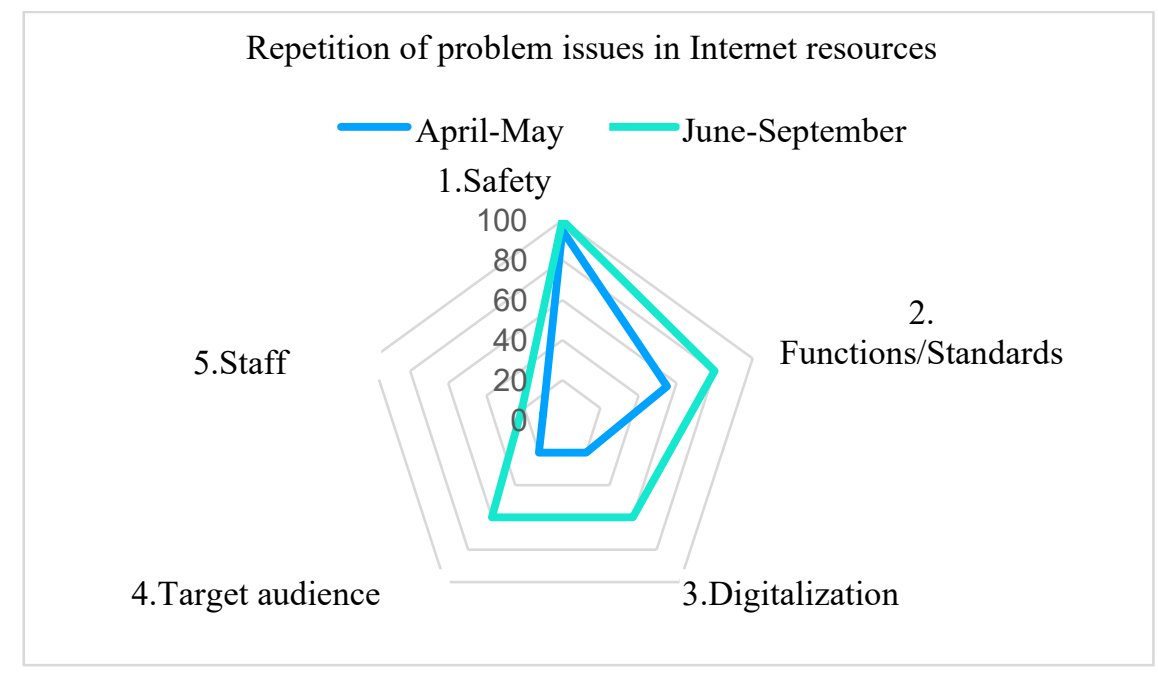

Fig. 1. Content analysis results of specialized information sites

4) target audience of hotels during the pandemic and post-pandemic period related to the changed demand for services, hotel orientation towards millennials and business guests, development of additional services and use of non-standard forms of MICE events in hotels;

5) staff, i.e. changed work schedule and regulations, a combination of duties of employees from different departments, transfer of some staff to remote work, staff reduction.

The content analysis made it possible to systematise five problem areas by the level of their relevance for the use of innovations (Fig. 1). The results given in Fig. 1 allow to speak about the problems that are most widely discussed in various information sources - safety, service standards, staff.

It is illustrative that the American Hotel \& Lodging Association, when developing the "Safe Living" rules, pays attention to three parameters: cleaning and hygiene, contactless solutions and additional services [4]. 
The peculiarity of the Russian response to challenges in case of the COVID-19 pandemic is related to the normative approach, namely: decisions of the Government of the Russian Federation, recommendations of the Federal Service for the Oversight of Consumer Protection and Welfare, orders of Governor of St. Petersburg A.D. Beglov. It was found out during the survey of hoteliers of St. Petersburg (Fig. 2) that 54\% of respondents considered it necessary to introduce the recommendations of the Federal Service for the Oversight of Consumer Protection and Welfare to the professional standards with due regard to the epidemiological situation, $18 \%$ of respondents considered that the recommendations would be legitimatised over time, $14 \%$ of respondents considered such recommendations as temporary measures as the pandemic would end soon, and remaining $14 \%$ of respondents considered changes unnecessary.

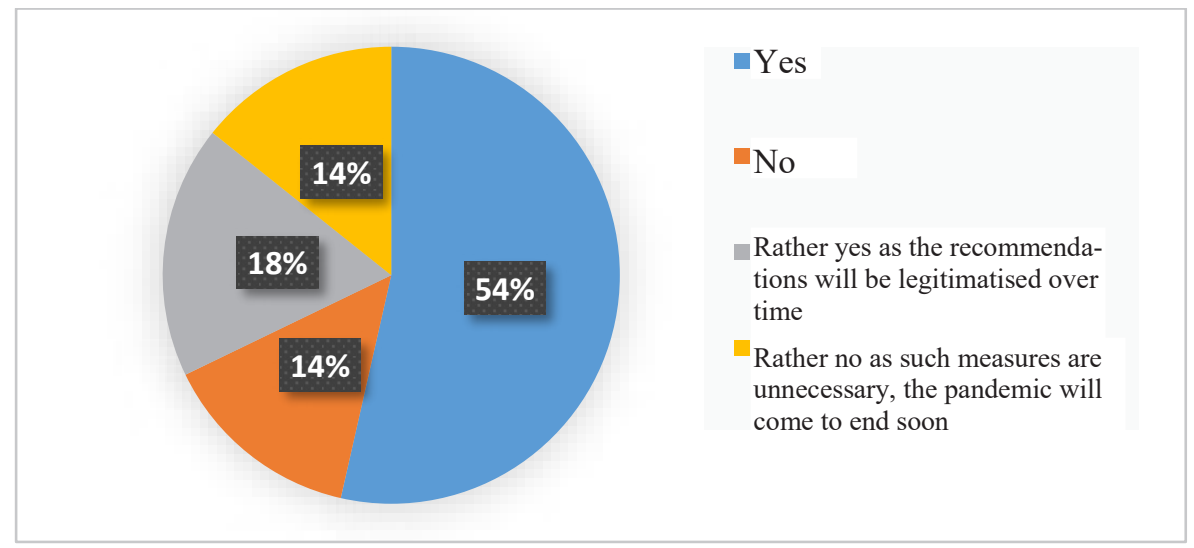

Fig. 2. Survey results of St. Petersburg hotels concerning changes in professional standards with due regard to the epidemiological situation (December 2020)

It should be noted that the question concerning the necessity of changes to the corporate standards in connection with the recommendations of the Federal Service for the Oversight of Consumer Protection and Welfare with the prolonged effect was positively answered by $54 \%$ of respondents in total, although totally $46 \%$ of respondents considered such measures unnecessary.

The survey of St. Petersburg hotel facilities showed that $90 \%$ of them had made various changes to the corporate standards by the time of the survey - October 2020. It can be concluded from the diagram (Fig. 4) that such changes were mostly made to safety standards. 


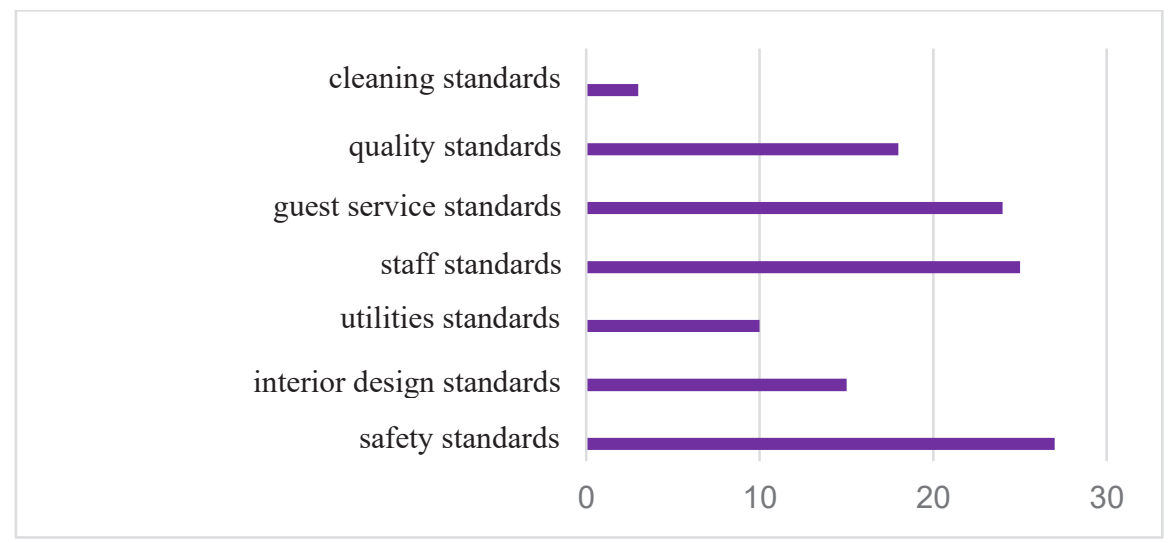

Fig. 3. Nature of changes made to the corporate standards of St. Petersburg hotel facilities as of December 2020

Therefore, during the period of restricted operation of hotel facilities and during the next period of the gradual renewal of operation of St. Petersburg hotels, considering the relevance of the normative approach in the conditions caused by the COVID-19 pandemic, the development and introduction of new safety standards have a long-term, regularly prolonged effect. Here, it is necessary to note the widely spread foreign and domestic practices in using the safety standards as a particular case in the development and use of corporate standards of hotels.

The comprehensive approach to the development of measures that make it possible to change the idea of the internal standards of hotels and their use should be treated as the innovative practice for ensuring guest safety in hotels:

$>$ development of safety programs, for example, Hilton CleanStay Room Seal, or the Managing Company Cosmos Hotel Group that was the first in the Russian hotel service market to have implemented the standards of hygienic and disinfecting procedures for all hotels of the network;

$>$ dynamically optimized working protocols with the use of mobile applications that make it possible not only regularly to update the internal cleanliness maintenance standards but also to assist the staff, as well as to use them for staff training, moreover, the staff training in standards becomes as important as the development of standards during the pandemic [5]

$>$ change in the hotel accommodation procedure, thus, the number of inquiries for early check-in and late check-out has increased by $13 \%$ and $34 \%$, correspondingly, in the world, that represent the wish of guests not to stay long in hotel lobbies omitting interim stages of accommodation, and of course, the role of digital contactless technologies is growing to a considerable extent [6]

$>$ design oriented towards the creation of interesting and conformable space in a hotel should combine with safety and modern cleanliness criteria, cleaning rules.

In particular, the Top Clean And Safety protocol additionally strengthens the existing measures by combining the recommendations of the World Health Organization (WHO), Centers for Disease Control (CDC), Federal Service for the Oversight of Consumer Protection and Welfare and local healthcare bodies providing information about COVID-19. 


\section{Assessment of the degree of the formed environmental awareness in Generation Z}

Recently, the term "environmental awareness" has been widely used both by mass media and individual bloggers. The environmental awareness is not a human feature but a conscious choice to introduce environmentally friendly habits in own life not only by following the trends but also by being aware of the importance of changes in the way of life and supporting "green" initiatives. The "Go green" slogan has been recently consolidated in advertising campaigns of the companies engaged in different kinds of business.

Becoming "green" or environmentally aware can have different forms, but the main meaning of this appeal is to be thoughtful as to the environment, be aware of that everyone influences it and commercially support the environmentally friendly goods and services. To be environmentally friendly is to be aware of that the contribution of everyone to careful attitude to the environment is important and even minimum efforts deliver benefits. There are multiple "green" practices that can be easily implemented, for example, when going to the supermarket, a single-use plastic bag can be replaced with a canvas bag that is comparable with several plastic bags by volume. When buying it, it may seem expensive, but it pays itself after 10 visits to the shop. At this, it will not degrade for a long period of time, and thus, it will considerably pay itself in contrast to the plastic bag that becomes torn in the way from the car to the flat, at the very best, it will be put into the bag with bags and become torn next time. In the large supermarkets such as "Lenta", there are also the machines where one can deliver plastic bottles and batteries for recycling, and then get allowances for purchases. People who are ready to spend more time for their environmentally friendly habits can use "green" cards specifying the reception points for different kinds of plastic, batteries, glass, etc. Such cards are intended for different cities of Russia, and recyclemap.ru for St. Petersburg. To summarize, the environmental awareness is not a human feature but a long way we are passing through. We begin introducing environmentally friendly habits in our life not only by following the trends but also being aware of the importance of changes in the way of life and supporting "green" initiatives.

Let's consider the mechanisms of formation of environmental awareness based on the thesis that the environmental awareness means understanding of delicacy of the environment and the importance of its protection. It includes many practices: going back from consumption culture to rational consumption, responsible attitude to oneself - choosing the healthy way of life [7], to nature and resources, economic support of manufacturers that undertake a set of measures to reduce the influence on the environment, use "green" technologies, such as reception of old clothes for recycling, use of alternative energy sources, environmentally safe materials, energy efficient equipment, etc.

Pop culture is a powerful mechanism of the formation of images associated with any phenomenon and consequently influencing the evolving habits. Generation $\mathrm{Z}$ has absolutely other tools for communication with the world. It not so much perceives the images rendered by pop culture as distinguishes key ideas in them, and the more images, the more ideas for the formation of a general picture.

In the beginning of the millennium, many public figures became focusing on global ecological problems, they were the actors of films and serials the generation grew up on and singers whose songs they listened to. Respectively, many people grew up among concerns about the state of the environment rendered by people who were loved, respected and whose success and lives were followed. This engagement in the lives of foreigners, in fact, who were concerned of consequences of the human influence on the environment, was then transmitted to the young generation. Public persons, whose acts are regularly followed by bloggers in social media, sent a simple message to generation $\mathrm{Z}$ : not the parents but they and their children will face the consequences of global ecological problems. And this means that 
the thing directly relating to the young generation cannot be taken with irony. That is why generation $\mathrm{Z}$ supports provocative acts highlighting the ecological problems and emotional speeches of Greta Thunberg. Her words stating that "her moral responsibility is to do what she can do" reflects this environmental awareness of generation $\mathrm{Z}$ many people strive for, as well as concerns of millions of people about the future of the world they live in.

The wish to move towards the environmental awareness directly depends on the amount of emotional and financial resources, as well as the wish for changes and improvement of the quality of life. This may be the reason for the older generation to treat eco-protests with a degree of scepticism and consider them as on-trend. But it should be noted that the 2019 expertise showed the reverse: a set of measures aimed at attracting the attention of public to climatic changes has arisen a large-scale ecological protest. On the very first day, over $4 \mathrm{mln}$. people from over 160 countries took part in it. This suggests that generation $\mathrm{Z}$, which engagement in global events is considerably higher than that of the previous generations, therefore, the attitude towards them should be more thoughtful and conscious.

The environmental awareness also becomes popular in the sphere of tourism. Many tourists choose eco-oriented accommodation facilities since the eco-concept corresponds to their way of life. Hotels called themselves as eco-hotels follow the concept of environmental awareness in all respects: from selection of environmentally safe materials for buildings, careful attitude to the environment, staff training in conscious consumption, probable refusal from energy consumption and minimization of water resource consumption. Considering the development trends of country recreation in the current epidemiological situation, such hotels are of great relevance now and will be relevant undoubtedly in the next decades since they are an attractive recreation option for generation $\mathrm{Z}$ [8].

The second part of the research was aimed at assessing the degree of the formed environmental awareness in students as representatives of generation $Z$ and future specialists in hospitality industry. The authors interviewed the third-year students of the Saint Petersburg State University of Economics studying the specialty "Hotel Business" and of the Saint Petersburg State University of Industrial Technologies and Design studying the specialty "Tourism", whose average age made 20-22 years old. Totally 168 people took part in the survey, among them: boys $-17 \%$ and girls $-83 \%$. The question "I am familiar with the essence and content of the notion "environmental awareness" was answered as follows: "yes" $-35 \%$, "partially" - 36\%, "no" - 29\%; the question "I am familiar with "green technologies" in tourism and hospitality" was answered as follows: "yes" - $82 \%$, "partially" - 17\%, "no" $-1 \%$; the question "I participated in the ecological projects" was answered as follows: "yes" $-37 \%$, "partially" $-18 \%$, "no" - 45\%; the question "I agree with the necessity to study ecological problems in the framework of professional training" was answered as follows: "yes" $-63 \%$, "partially" $-35 \%$, "no" $-2 \%$; the question "What I am studying is closely connected with my professional practice" was answered as follows: never $-7 \%$, rarely $-6 \%$, sometimes $-19 \%$, often $-34 \%$, - almost always $-32 \%$. Therefore, the overwhelming majority of respondents note that the ecological problems arise considerable interest in students, as well as allow to develop professional skills in the course of training. It can be stated that the degree of environmental awareness in students is quite high and of practiceoriented nature.

This is also evidenced by design activity results in the course of studying the professional disciplines where students develop the projects of the modern types of accommodation facilities that meet all requirements set forth to the ecological accommodation facilities. In their projects, they use innovative technologies, environmentally friendly materials, as well as various educational programs as additional services. An example can be the "Pinewood" eco-glamping project that is supposed to locate in Priozerny district of Leningrad region. The target audience of the projected glamping: individual travellers - conscious-travellers, for 
whom it is important not only to get new impressions but also to support careful attitude to the environment.

The "Environmental Awareness" program is offered for eco-glamping guests as one of the additional services. There are various methods of promotion of environmental awareness in the hospitality industry: entry into "green programs" and obtaining the certificates of the company environmental friendliness, use of returnable items for the staff, various nozzles and appliances for water saving, motion sensors for light equipment, and so on. However, all these measures should be accompanied not only by an explanation of what they are intended for, but also by particular acts. For example, by supporting the separate collection of waste in the glamping, the guests assist in preventing the appearance of illegal garbage dumps in the region, reduce the load on the existing ones, and so on. Here is a set of measures in the framework of the "Environmental Awareness" program: location of the service for reception and placement of containers for separate collection of waste and its further delivery for recycling; waste stockpiling by guests in special paper bags available in each room; search of collection points for various kinds of plastic and batteries to be chosen according to the map; brief memory card on the importance of the separate collection of waste, economic use of water and electricity in rooms.

These are the programs that make the people lives environmentally aware. Moreover, the offered glamping project allows to form competencies in the future professional activity of students from the point of view of environmental awareness.

\section{Conclusion}

The pandemic caused not only economic losses to the hotel business but also learnt the representatives of the hotel business to work in the new format of uncertainty quickly responding to the necessity of prompt actions in solving new, previously unknown tasks both regarding guests and staff. The country hotel facilities with the use of "green technologies" became rapidly developing since the consumer preferences, as well as the target audience have changed.

The formation of environmental awareness in the hospitality service consumers and in the professional activity of the hotel employees is a complex process that will take a lot of years. By creating the programs of formation of environmental awareness, moreover, by creating the required conditions for their implementation, people all over the world will join the culture of environmental awareness and environmental consumption. Today, this can be called a trend among generation $\mathrm{Z}$, however, in a couple of decades, if supported by the professional community and representatives of the territorial authorities, the environmental awareness will become a part of our life and the way of life. Opening of eco-hotels, use of "green technologies" at the tourist and hotel facilities, organization of a separate collection of waste, waste disposal, and so on form the reference points in the development of hospitality facilities.

Creating such a format of ecological accommodation facilities will allow to:

- economize resources for the functioning of the accommodation facility to ensure comfortable staying of guests in the natural environment;

- form sustainable environmental awareness in the professional activity of hoteliers;

- impart skills of careful attitude to resources and nature, in general, to the hotel services consumers;

- scale up the process of formation of environmental awareness among youth not only in theory but in practice. 


\section{References}

1. O. Arkhipova., Y. Vladykina., N. Donets., O. Osipova., G. Uryupina, 13th International Scientific and Practical Conference on State and Prospects for the Development of Agribusiness, 10003 (2020)

2. Market situation of hotel real estate in St. Petersburg according to MARIS in the CBRE Association, https://maris-spb.ru/

3. Bare figures: operational performance of hotel segment 2020, https://www.cafefuture.ru/

4. Hotels After Coronavirus: What Happens After a Pandemic, https://www.plugandplaytechcenter.com/

5. Ahla releases industry-wide hotel cleaning standards through "safe stay" initiative, https://www.ahla.com/

6. Upselling During a Pandemic: Early Check-In and Late Check-Out, https://www.hospitalitynet.org/

7. O. Nikitina, Journal of Social Studies Education Research, 9(2), 317 (2018)

8. "Green" hotels - the unconditional trend of recent years, News of ABT-ACTE Russia, http://www.businesstravelrussia.ru/ 